\title{
Modeling the Spill in the Songhua River after the Explosion in the Petrochemical Plant
} in Jilin

\section{Fu, Wenjing; Fu, Huijin; Skøtt, Karen; Yang, Min}

\section{Published in:}

Environmental science and pollution research international

Link to article, DOI:

10.1065/espr2007.11.457

Publication date:

2008

Document Version

Publisher's PDF, also known as Version of record

Link back to DTU Orbit

Citation (APA):

Fu, W., Fu, H., Skøtt, K., \& Yang, M. (2008). Modeling the Spill in the Songhua River after the Explosion in the Petrochemical Plant in Jilin. Environmental science and pollution research international, 15(3), 178-181. https://doi.org/10.1065/espr2007.11.457

\section{General rights}

Copyright and moral rights for the publications made accessible in the public portal are retained by the authors and/or other copyright owners and it is a condition of accessing publications that users recognise and abide by the legal requirements associated with these rights.

- Users may download and print one copy of any publication from the public portal for the purpose of private study or research.

- You may not further distribute the material or use it for any profit-making activity or commercial gain

- You may freely distribute the URL identifying the publication in the public portal 


\title{
Area 2.2 • Modeling of Chemicals in Water
}

\section{Research Article}

\section{Modeling the Spill in the Songhua River after the Explosion in the Petrochemical Plant in Jilin*}

\author{
Wenjing Fu**, Huijin Fu, Karen Skøtt and Min Yang \\ Institute of Environment \& Resources DTU, Technical University of Denmark, 2800 Kongens Lyngby, Denmark
}

**Corresponding author (wenjingfu@gmail.com)

\section{DOI: http://dx.doi.org/10.1065/espr2007.11.457 \\ Please cite this paper as: Fu W, Fu H, Skøtt K, Yang M (2008): Modeling the Spill in the Songhua River after the Ex- plosion in the Petrochemical Plant in Jilin. Env Sci Pollut Res 15 (3) 178-181}

\section{Abstract}

An explosion in a petrochemical plant in Jilin in the northeast of China on 13 November 2005 was responsible for the discharge of large quantities of benzene and nitrobenzene into Songhua River. This endangered the water supply of Harbin city and influenced the daily life for millions of people. The dispersion-advection equation was solved analytically and numerically and used to simulate the concentration of benzene and nitrobenzene in the Songhua River after the accident. Both solutions gave practically identical results. The main elimination process for both compounds was volatilization. The model results are quite close to the results obtained by measurements at monitoring stations. Arrival time of the pollutant wave, peak concentrations and end of the pollutant wave at Harbin and along the river were predicted successfully. The peak concentrations of nitrobenzene at Harbin were more than 30 times above the permissible limits for drinking water.

Keywords: Accidents; benzene; chemical industry; China; Harbin; Jilin; model; nitrobenzene; petrochemical plant; Songhua River; spills

\section{Introduction}

On the 13 November 2005, at 13:00 pm, an explosion occurred at the Jilin Chemical Industrial Co., a subsidiary of the China National Petroleum Corporation Plant, located in Jilin Province. Five people died and more than 70 others were injured (Tan 2005). Approximately 100 tons of a mixture of benzene, nitrobenzene and other toxic compounds were spilled into the Songhua River (UNEP 2005). Harbin, which is the capital of the Heilongjiang Province, is located approximately $500 \mathrm{~km}$ downstream from the explosion scene (Fig. 1). The pollution front was expected to arrive at Sifang Tai, one of Harbin's monitoring points, at 5 am on November 24, 2005, and since Songhua River is responsible for $90 \%$ of the water supply to Harbin, the water supply was cut off from midnight on November 23, 2005.

To our knowledge, except for a UNEP report (UNEP 2005), no scientific study of this accident has been published so far.

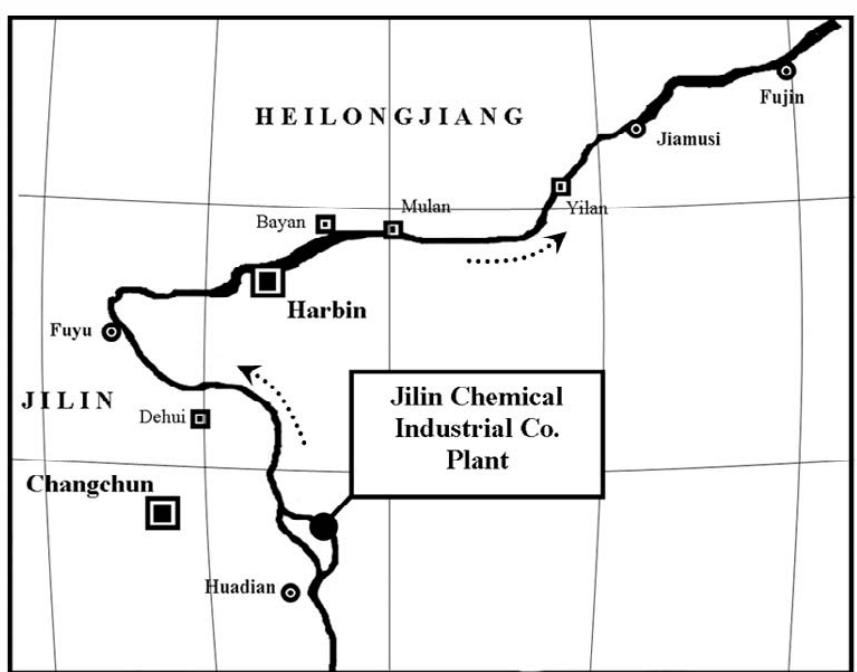

Fig. 1: Map of Songhua River (China) from the explosion scene to Harbin The arrows indicate the flow direction of the river water

Here, dispersion-advection models have been used to simulate and interpret the transport of the pollution wave in the Songhua River downstream of the explosion point. The results were compared to the measured concentrations in the river and to legal standards.

\section{Methods}

\subsection{Model Implementation}

The downstream transport of chemicals in rivers after pulse emissions (accidents) is described by the dispersion-advection equation (Trapp \& Matthies 1998):

$$
\frac{\partial C}{\partial t}=\frac{\partial D \partial C}{\partial x^{2}}-\frac{\partial(u C)}{\partial x}-\lambda C
$$

where

$\mathrm{C}$ is the concentration in the river water $\left[\mathrm{mg} \mathrm{m}^{-3}\right]$, $\mathrm{t}$ is the flow time $[\mathrm{s}], \mathrm{D}$ is the dispersion coefficient $\left[\mathrm{m}^{2} \mathrm{~s}^{-1}\right]$, $\mathrm{u}$ is the flow velocity $\left[\mathrm{m} \mathrm{s}^{-1}\right]$ and $\lambda$ is a first-order loss rate.

ESS-Submission-Editor: Stefan Trapp (stt@er.dtu.dk) 
Both analytical (IKSR 1991, Brüggemann et al. 1991) and numerical solutions (Reichert \& Wanner 1987) of this equation have been used to simulate chemical spills in rivers. A basic analytical solution, assuming constant conditions and pulse input, is

$$
C(x, t)=\frac{\frac{m_{0}}{A}}{\sqrt{4 \pi D t}} \cdot e^{\frac{(x-u t)^{2}}{4 D t}} \cdot e^{-\lambda t}
$$

where

$\mathrm{m}_{0}$ is the emitted mass of chemical [kg],

$\mathrm{A}$ is the river cross-sectional area $\left[\mathrm{m}^{2}\right]$ and

$\mathrm{x}$ is the distance from release $[\mathrm{m}]$.

An easy numerical solution of the dispersion-advection equation uses the explicit finite-difference method. The numerical dispersion is made equal to the real dispersion in the river by appropriate selection of time and space grid under consideration of the Courant-criterion (Trapp \& Matthies 1998). Subsequently, the dispersion term can be omitted from the equations. The resulting iteration scheme is

$$
C_{i, j+1}=C_{i, j}-\frac{u}{\Delta x} \cdot\left(C_{i, j}-C_{i-1, j}\right) \cdot \Delta t-\lambda \cdot C \cdot \Delta t
$$

where

$\mathrm{i}$ is the step in $\mathrm{x}$-direction, and $\mathrm{j}$ in t-direction.

Numerical and analytical solution gave practically the same result. Below, only results obtained with the analytical solution are shown.

The elimination constant $\lambda$ is the sum of all elimination processes. However, for benzene and nitrobenzene, sedimentation, photo- and biodegradation were neglected due to the low sorption coefficient $K_{d}$ and the low temperature and light of the river in winter. The loss from water was subsequently assumed to be due to volatilization of the compounds and calculated with the two-film theory (Trapp \& Harland 1995):

$\frac{1}{\lambda_{V}}=\frac{h}{1 / k_{l}+1 / K_{A W} k_{g}}$

where

$\mathrm{y}$ is the rate for loss via volatilization (1/time),

$\mathrm{k}_{1}$ is conductance of the liquid film [length/time],

$\mathrm{k}_{\mathrm{g}}$ is conductance of the gaseous film [length/time],

$\mathrm{h}$ is average river depth [m] and

$\mathrm{K}_{\mathrm{AW}}$ is the partition coefficient air-water of the chemical.

The regression equations of Southworth (1979) for rivers were used to calculate the exchange velocities, for the liquid film

$k_{l}=0.2351 \times u^{0.969} \times h^{-0.673} \times \sqrt{\frac{32}{M}} \quad(\mathrm{~m} / \mathrm{h})$

where

$M$ is the molar mass of the chemical and

$u$ is the flow velocity $\left(\mathrm{m} \mathrm{s}^{-1}\right)$.

The conductance of the gaseous film was calculated as

$k_{l}=11.37(v+u) \times \sqrt{\frac{18}{M}} \quad(\mathrm{~m} / \mathrm{h})$

where

$v$ is the wind speed (here: set to zero).

\subsection{Data}

The input data for benzene and nitrobenzene are shown in Table 1. The released amounts of benzene and nitrobenzene were fitted. The other parameters were taken from the website of the HINC Heilongjiang Information Network of China (2006) and other sources.

\begin{tabular}{|c|c|c|c|c|}
\hline Parameter & Symbol & Value & Units & Reference \\
\hline Input of benzene & $\mathrm{m}$ & 7.5 & tons & fitted \\
\hline Input of nitrobenzene & $\mathrm{m}$ & 92.6 & tons & fitted \\
\hline Partition coefficient air-water of benzene & $\mathrm{K}_{\mathrm{AW}}$ & 0.23 & & Rippen (2006) \\
\hline Elimination rate of benzene & $\lambda$ & 0.182 & $D^{-1}$ & calculated \\
\hline Cross area of the river & A & 1,480 & $m^{2}$ & HINC (2006) \\
\hline Width of the river & W & 370 & $\mathrm{~m}$ & HINC (2006) \\
\hline Dispersion coefficient & $\mathrm{D}$ & 500 & & Typical value (Trapp \& Matthies 1998) \\
\hline Flow velocity & $\mathrm{u}$ & 0.53 & $\mathrm{~m} \mathrm{~s}^{-1}$ & estimated \\
\hline Molar mass of benzene & M & 78 & $\mathrm{~g} \mathrm{~mol}^{-1}$ & Rippen (2006) \\
\hline Molar mass of nitrobenzene & M & 123.11 & $\mathrm{~g} \mathrm{~mol}^{-1}$ & Rippen (2006) \\
\hline Partition coefficient air-water of nitrobenzene & $\mathrm{K}_{\mathrm{AW}}$ & 0.0029 & & Rippen (2006) \\
\hline Elimination rate of nitrobenzene & $\lambda$ & 0.0318 & $D^{-1}$ & calculated \\
\hline Water depth & $\mathrm{h}$ & 4 & $M$ & estimated \\
\hline Wind speed & v & 0 & $\mathrm{~m} \mathrm{~s}^{-1}$ & assumption \\
\hline
\end{tabular}

Table 1: Input data used for the simulations 
The measured data of benzene were collected from the public report released by the Environmental Protection Bureau of Heilongjiang Province. These data were monitored by the Heilongjiang Environmental Monitoring Centre and at the Jiamusi Environmental Monitoring Station. The measured data of nitrobenzene were collected from the UNEP expert team report (UNEP 2005).

\section{Results and Discussion}

Benzene. Fig. 2 shows the result of the analytical solution for the concentration of benzene at Harbin compared to the measured data. The agreement is not completely unexpected, since the input of benzene was fitted. However, also the shape of the curve and the peak arrival are in good agreement. The river water concentration of benzene at Harbin is throughout below the Chinese permission level of $0.01 \mathrm{mg} / \mathrm{L}$ (UNEP 2005).

Nitrobenzene. The results for nitrobenzene are shown in Fig. 3. Again, simulations and measurements are in good agreement. A deviation is seen for the second measured concentration $(t=10.5 \mathrm{~d})$. This might indicate that dispersion, which drives the width of the peak, was overestimated. The release of nitrobenzene into the river was much higher than the release of benzene, and much higher concentrations were measured at Harbin. The guideline for nitrobenzene in drinking water in China is $0.017 \mathrm{mg} / \mathrm{l}$, which was exceeded significantly at the time the pollution wave passed Harbin on November 23, 2005 (UNEP 2005). The peak concentration was $0.58 \mathrm{mg} / \mathrm{l}$, which is about 33 times the permitted level.

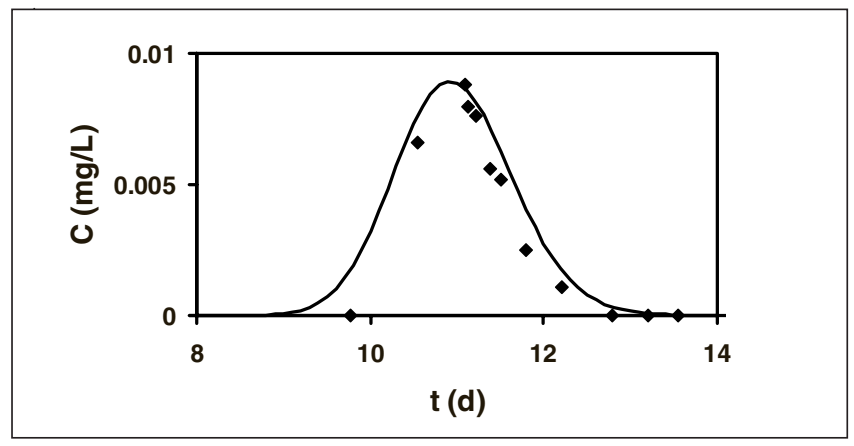

Fig. 2: Comparison of the calculated and the measured concentration of benzene in the Songhua River at Harbin after the accident

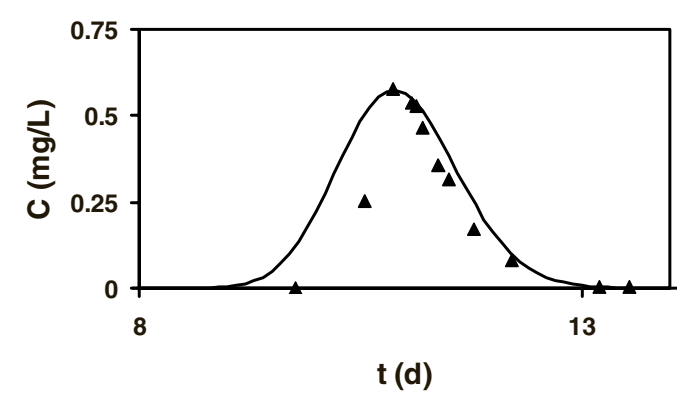

Fig. 3: Comparison of the calculated and the measured concentration of nitrobenzene in the Songhua River at Harbin after the accident

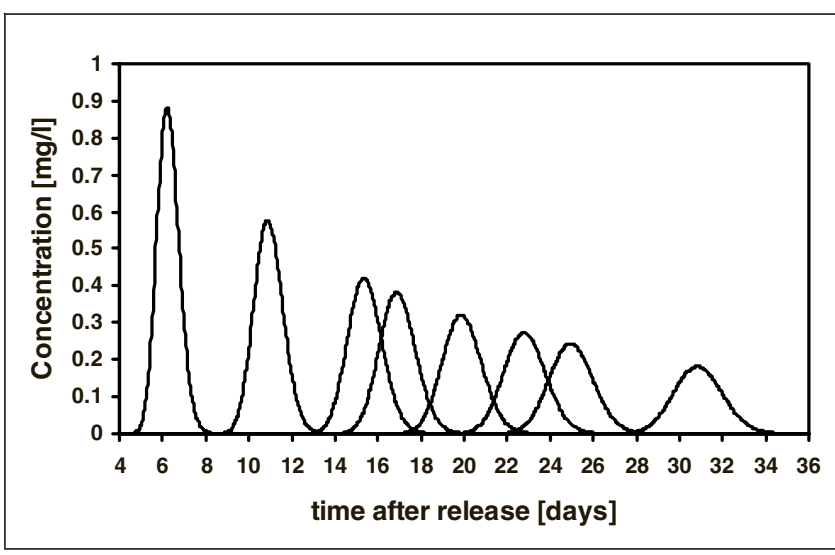

Fig. 4: Concentration of nitrobenzene along the Songhua River estimated with the analytical model at the following monitoring stations: 1 . Songyan (286 km); 2. Harbin (500 km); 3. Mulan (705 km); 4. Tonghe (775 km); 5 Yilandal (912 km); 6. Pre-Jiamus (1046 km); 7. Jiamus (1145 km); 8. Fujin $(1415 \mathrm{~km})$

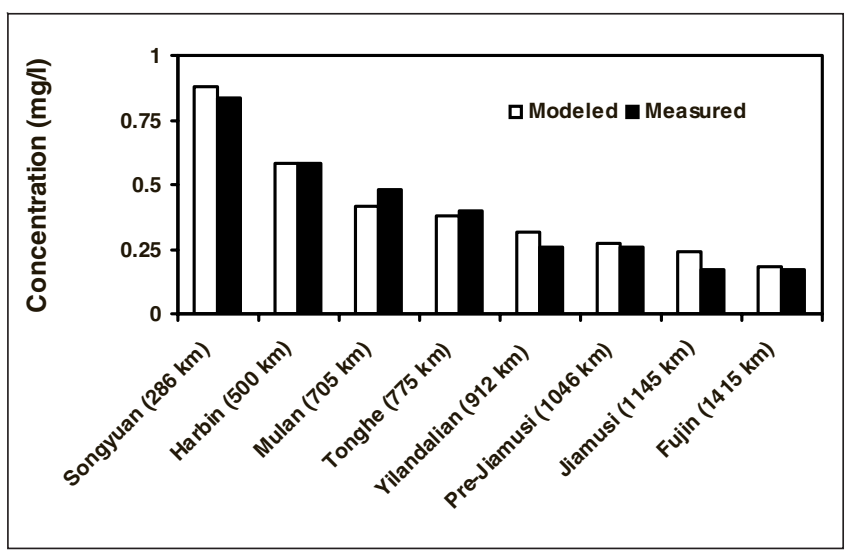

Fig. 5: Comparison of predicted and measured peak concentration of nitrobenzene along the Songhua River

The simulation of the concentration of nitrobenzene along the Songhua River versus time is shown in Fig. 4. The peak broadens and the maximum concentrations decrease with distance and flow time, due to dispersion. There is also a decrease of pollutant mass (represented by the area below the curve), which is due to volatilization of the chemical from the river water into air. Nevertheless, the peak concentration at the Fujin monitoring station $1415 \mathrm{~km}$ downstream and 31 days after the accident is still 10 times above the permissible level of $0.017 \mathrm{mg} / \mathrm{l}$ for drinking water in China. The comparison between measured and calculated peak concentration of nitrobenzene is shown in Fig. 5. The small differences between calculated and measured concentrations of nitrobenzene might be explained by the variation of the width and depth of the river, which the model did not account for.

\section{Conclusions}

The concentrations of benzene and nitrobenzene in the Songhua River after the accident in Jilin could be successfully calculated and interpreted using an analytical or a nu- 
merical solution of the one-dimensional dispersion-advection equation. The simulations could predict the time of arrival of the pollutant wave, the peak concentrations and the end of the pollutant wave at Harbin and along the river. The model results and the measurements along the river indicate that the contamination with benzene was less serious than the contamination with nitrobenzene. This was probably due to the higher amount of nitrobenzene released during the accident. According to the model simulations, the elimination in the river was mainly due to volatilization, while photolysis and biodegradation were low, due to winter conditions.

Acknowledgements This study was prepared as project work in the course 12233 Water Pollution at the Technical University of Denmark under supervision of the course coordinator Stefan Trapp. We want to thank our teacher for the interesting course and for help with the manuscript.

\section{References}

Brüggemann R, Trapp S, Matthies M (1991): Behaviour assessment for a volatile chemical in the Rhine River. Environ Toxicol Chem 10, 1097-1103

HINC Heilongjiang Information Network of China (2006)

http://www.hljxxw.gov.cn/sqgl/dxqh/t20051115_3204.htm, accessed 21 Nov 2006
IKSR Internationale Kommission zum Schutz des Rheins (1991): Rhine alarm model 2.0. Report-no. II-4 of the KHR, Koblenz, D (in German)

Reichert P, Wanner O (1987): Simulation of a severe case of pollution of the Rhine River. Proceedings of the Twelfth Congress of the International Association of Hydraulic Research, Lausanne, Switzerland, Aug. 31-Sept. 4. Water Resources, Littleton, CO, pp 239-244

Rippen G (2006): Handbuch Umweltchemikalien. ecomed, Landsberg am Lech, Germany

Southworth GR (1979): The role of volatilization in removing polycyclic aromatic hydrocarbons from aquatic environments. Bull Environ Contam Toxicol 21, 507-511

Tan F (2005): Toxic threat watered down in Harbin. Asian Chemical News 11 (517) 11

Trapp S, Harland B (1995): Field test of volatilization models. Env Sci Pollut Res 2 (3) 164-169

Trapp S, Matthies M (1998): Chemodynamics and environmental modeling, Springer, Berlin, Germany

UNEP United Nations Environment Programme (2005): Chinese River Contamination Resulting from A Petrochemical Explosion and Toxic Spill. http://www.uneptie.org/pc/apell/disasters/ china_harbin/info.htm and http://www.uneptie.org/pc/apell/disasters/china_harbin/unepmr.pdf, accessed 21 Nov 2006

http://www.uneptie.org/pc/apell/disasters/china_harbin/unepmr.pdf

United Nations Environment Programme - The Songhua River Spill China, December 2005: Field Mission Report

\section{Introduction}

1.1 Background to the spill

1.2 Scope of the mission

1.3 Mission team

1.4 Meteorological conditions

\section{Observations and Discussions}

2.1 Description of the Songhua River Spill

2.2 Coordination of response

2.3 Emergency pollution monitoring

2.4 Pollution control and mitigation measures

2.5 Information and communication

2.6 Medium and long term measures

2.7 Cooperation and coordination with Russia in monitoring and response

2.8 Limitations to the mission 14

\section{Conclusions and Recommendations}

Annex 1. Itinerary of the UNEP Mission on Songhua River Chemical Spill

Annex 2. Fact sheet of Benzene, Nitrobenzene and Aniline

Annex 3 Key resource persons to the mission

Annex 4. UNEP Field Team 